\title{
Delegation of Germany XIII-2781-19 Application of high frequency mechanical impact treatment to improve the fatigue strength of corroding welded joints
}

\author{
J. Weinert ${ }^{1} \cdot$ S. Gkatzogiannis ${ }^{2} \cdot$ I. Engelhardt ${ }^{1}$ D $\cdot$ P. Knoedel ${ }^{2} \cdot$ T. Ummenhofer $^{2}$
}

Received: 8 March 2021 / Accepted: 10 August 2021 / Published online: 10 September 2021

(c) The Author(s) 2021

\begin{abstract}
This study deals with the fatigue strength of high-frequency mechanical impact (HFMI)-treated unprotected structural details made of mild steel $S 355$ considering the influence of corrosive environmental conditions. The investigations are carried out on butt welded specimens with sheet thickness $t=15 \mathrm{~mm}$ and on transverse non-load-carrying attachment specimens with sheet thickness $t=25 \mathrm{~mm}$. Two different methods were applied for the simulation of marine corrosive environment in the laboratory. Specimens first were deposited in a salt spray chamber and then tested subsequently dry at laboratory-air conditions considering the influence of corrosion on the crack initiation. Alternatively, and to cover the effects of corrosion on the crack growth, artificial seawater was used for pre-corrosion, and after a defined timespan, fatigue tests were performed simultaneously with the specimen resting in the corrosive medium. The corrosion fatigue tests were performed in as-welded and HFMI-treated conditions at a stress ratio $R=0.1$ under axial tensile and 4-point bending cyclic loading. The test results are evaluated to determine the characteristic fatigue strengths for fixed slopes $m=3$ and $m=5$ according to IIW recommendations for the as-welded and for the HFMI-treated condition respectively. The results of the experimental investigations based on the nominal stress approach show that the fatigue strength of both specimen types could be significantly increased by the application of HFMI treatment compared to the corresponding specimens in the as-welded condition even if exposed to the investigated corrosive conditions. The comparison with the design proposals of IIW shows that for HFMI-treated butt welds, no reduction of the FAT class due to corrosion is required and the recommended FAT class is still valid. The results for the HFMI-treated transverse attachments are slightly below the design curve recommended by IIW and a proposal to consider corrosion is derived for this case. Additional numerical investigations by applying the effective notch stress (ENS) approach are performed to determine notch stress curves. It was found that for the corroded specimens in the as-welded condition, the FAT class according to IIW could not be reached and adjustments of the existing rules are necessary to consider corrosion effects. However, it can be concluded that the effective notch fatigue resistance recommended by IIW is still applicable in the case of corroded HFMI-treated structural details.
\end{abstract}

Keywords Fatigue strength · Corroded welded joints · S355 · High-frequency mechanical impact (HFMI) treatment · Corrosion fatigue $\cdot$ Effective notch stress design

Recommended for publication by Commission XIII-Fatigue of Welded Components and Structures

I. Engelhardt

Imke.engelhardt@hm.edu

1 Laboratory for Steel and Lightweight Structures, Institute for Material and Building Research, University of Applied Sciences Munich, Munich, Germany

2 Research Center for Steel, Timber \& Masonry, KIT Steel \& Lightweight Structures, Karlsruhe Institute of Technology, Karlsruhe, Germany

\section{Introduction}

Corrosion fatigue affects the fatigue strength of unprotected steel components [1], which can lead to a reduction of fatigue resistance [2]. Offshore support structures are exposed to fatigue loads and a highly corrosive environment so that corrosion fatigue can occur if corrosion protection is not provided. This can be decisive for the design of structures such as offshore wind turbines [3] if the surface protection system is assumed to be defect. Earlier studies of HFMI treatment methods summarized by Yildirim and Marquis [4] 
confirmed their applicability to increase the fatigue strength of welded joints. Based on these results, the recommendation for HFMI-treated welded joints [5] was presented by the International Institute of Welding. Considering the increased fatigue strength of HFMI-treated joints allows a more economic design of offshore structures. However, since the risk of corrosion cannot be completely prevented in situ, it is necessary to understand how a lack of corrosion protection can influence the fatigue strength in offshore applications and to provide verified design specifications. The guideline DNV-GL-RP-C203 [6] gives a 30\% reduction of the fatigue strength of as-welded details due to "free corrosion" and provides respective design curves. The proposal to reduce the predicted fatigue strength down to $70 \%$ in comparison to the corrosion-free case is also given by Hobbacher [7]. In general, complete corrosion protection is assumed. But the present rules and regulations do not provide any consideration of HFMI treatment in corrosive environments due to the largely unexplored field of research.

The goal of a research project conducted by the authors [8] was to quantify the influence of corrosion on the fatigue behaviour of HFMI-treated welds and investigate the effectiveness of the HFMI treatment in a marine corrosive environment. The characteristic fatigue strengths determined for a fixed slope based on the nominal and the notch stress approach are presented in this study. The findings are compared to the corresponding FAT classes recommended by IIW for the as-welded [7] and the HFMI-treated [5] condition. The design recommendations derived for both butt welds and transverse attachments in the HFMI-treated condition have previously been discussed in German [9] and English [10]. The influences of corrosion on the fatigue behaviour of the structural details investigated here are discussed in more detail in two further articles, separately for butt welds [11] and transverse attachments [12]. Supporting investigations regarding surface conditions and effects from corrosion on the HFMI-treated weld toe geometry are presented and discussed.

\section{Corrosion fatigue tests}

Fatigue tests have been performed to investigate the influence of marine corrosion on the fatigue strength of HFMItreated and as-welded structural details. To analyse the fatigue behaviour for the phases of crack initiation and crack growth individually, two different methods of pre-corrosion and subsequent testing were defined. Sequential corrosion fatigue tests have been conducted to analyse the influence of corrosion on the crack initiation behaviour. Initially, the specimens were pre-corroded in a salt spray chamber (SSC) according to a previous study [13] to reproduce marine environmental conditions. These specimens were subsequently dry tested at laboratory-air conditions. To investigate both the influence of corrosion on crack initiation and crack growth, simultaneous corrosion fatigue tests were carried out. First, the specimens were exposed to artificial seawater (ASW) considering [14] and then tested in this corrosive medium as well.

\subsection{Welded steel specimens}

The structural details butt weld and transverse non-loadcarrying attachment made of mild steel $S 355 J 2+N$ have been investigated in the HFMI-treated and the as-welded condition. After welding, the specimens were separated by water-jet cutting. To avoid edge cracks, the edges were subsequently ground. The weld toes of the specimens were HFMI-treated using the HiFIT device $\left(r_{\text {pin }}=1.5 \mathrm{~mm}\right)$ and the PITEC device $\left(r_{\text {pin }}=2.0 \mathrm{~mm}\right)$. The dimensions of the test cross sections of the specimens and the weld geometry parameters according to the welding procedure specifications are shown in Fig. 1.

\subsection{Test series of the present study}

An overview of the test series, which were investigated in this study, is shown in Table 1. The nomenclature of the test series shows the type of structural detail, the treatment condition of the test specimen, the pre-corrosion method, the test type, and the loading type. A stress ratio of $R=0.1$ was used throughout all test series.

The specimens of the sequential corrosion fatigue tests were pre-corroded in the SSC and subsequently dry tested. A neutral salt spray test was used, and a corrosion duration of 10 days was chosen to increase the surface roughness without a significant reduction of the thickness. A mean uniform reduction in sheet thickness of about $0.1 \mathrm{~mm}$ was documented. The sequential fatigue tests were carried out under cyclic axial tensile loading and cyclic 4-point bending. The specimens of the simultaneous corrosion tests were pre-corroded in ASW for 30 days and were re-dried under laboratory conditions in air for at least 10 days. The duration was based on the effect of the SSC tests regarding uniform thickness loss and surface roughness, to achieve comparable initial conditions. The simultaneous fatigue tests were performed under cyclic 4-point bending in a stainless steel chamber filled with artificial seawater. The test frequency was limited to $1 \mathrm{~Hz}$ to ensure sufficient exposure of the corrosive medium after crack initiation. This test frequency is comparable to the cyclic frequency range of real monopile structures exposed to alternating bending stress, which lies between 0.3 and $0.4 \mathrm{~Hz}$ [15]. As it was shown in Oberparleiter et al. [16], the influence of the test frequency in those ranges is negligible, especially if the crack initiation phase represents a significant part of the total fatigue life which 
Fig. 1 Geometry of the welded steel specimens: a butt weld and b transverse attachment a)
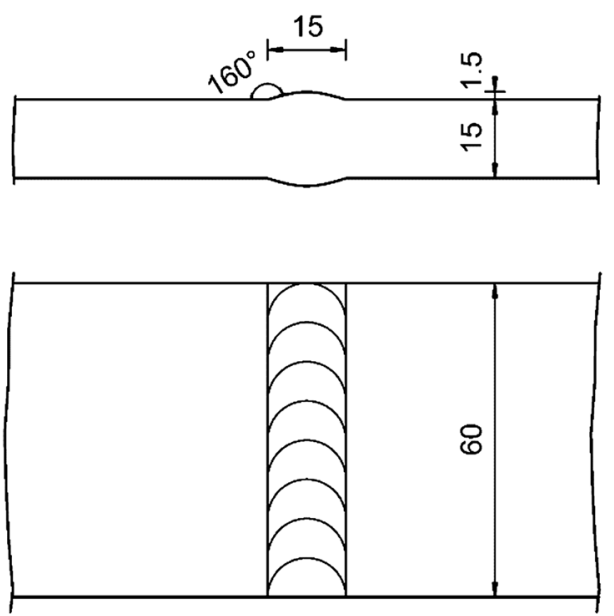
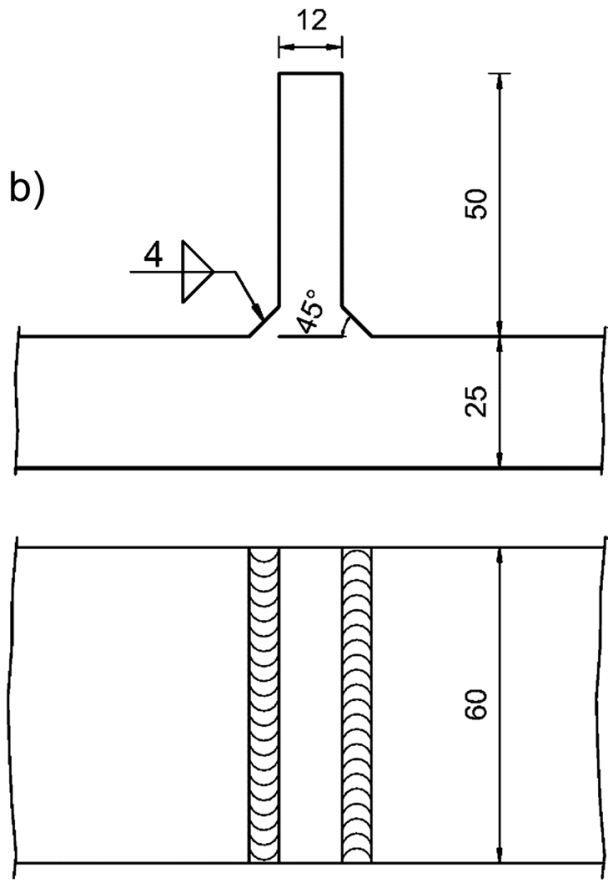

applies for HFMI-treated welds [17]. The methods used for laboratory corrosion and specific descriptions of the test setups for conducting the corrosion fatigue tests are described in more detail in [18] and also in ([11, 12]).

\section{Fatigue test results}

The test results are evaluated based on the nominal stress approach using $\mathrm{S}-\mathrm{N}$ curves. For the evaluation of the $\mathrm{S}-\mathrm{N}$ curves, the fixed slopes according to the IIW recommendations of as-welded [7] and HFMI-treated [5] structural details are used. The fatigue tests were performed until failure of the specimen occurred in the weld toe or the parent material. The number of load cycles up to failure of the test specimens is used for the evaluation of fatigue life. Failure of the specimens is attributed to a subsequently measured fracture surface of about 50 to $60 \%$ of the original cross section. A failure in the parent material is considered as the lower limit of the achievable fatigue life and is considered when calculating the fatigue strength. According to the document of Euler and Kuhlmann [19] concerning DIN EN 1993-1-9 [20], the one-sided 95\% prediction bound and the corresponding characteristic fatigue strength $\Delta \sigma_{c}$ (FAT) are calculated. For $\Delta \sigma_{c}$, the reference value is specified for $N=2 \cdot 10^{6}$ load cycles. Runouts and failure due to cracks occurring in the parent material are indicated in the diagrams. The results of the test series are compared with the corresponding regulations of IIW for as-welded [7] and HFMI-treated [5] structural details.

Table 1 Overview of the corrosion fatigue test program

\begin{tabular}{|c|c|c|c|c|c|}
\hline Test series & Structural detail & Condition & Pre-corrosion & Test type & Load type \\
\hline BW_AW_SSC_ax & Butt weld & As-welded & SSC for 10 days & Subsequently, dry & Axial tensile \\
\hline BW_HFMI_SSC_ax & Butt weld & HFMI-treated & SSC for 10 days & Subsequently, dry & Axial tensile \\
\hline BW_AW_SSC_b & Butt weld & As-welded & $\mathrm{SSC}$ for 10 days & Subsequently, dry & 4-point bending \\
\hline BW_HFMI_SSC_b & Butt weld & HFMI-treated & SSC for 10 days & Subsequently, dry & 4-point bending \\
\hline BW_AW_ASW_b & Butt weld & As-welded & ASW for 30 days * & Simultaneously in ASW & 4-point bending \\
\hline BW_HFMI_ASW_b & Butt weld & HFMI-treated & ASW for 30 days * & Simultaneously in ASW & 4-point bending \\
\hline TA_HFMI_SSC_ax & Transverse attachment & HFMI-treated & SSC for 10 days & Subsequently, dry & Axial tensile \\
\hline TA_AW_ASW_b & Transverse attachment & As-welded & ASW for 30 days * & Simultaneously in ASW & 4-point bending \\
\hline TA_HFMI_ASW_b & Transverse attachment & HFMI-treated & ASW for 30 days * & Simultaneously in ASW & 4-point bending \\
\hline
\end{tabular}

${ }^{*}$ re-dried under laboratory conditions in air for at least 10 days 
Table 2 Summary of the fatigue data for butt welds

\begin{tabular}{llllllll}
\hline Test series & $t(\mathrm{~mm})$ & $f_{y}(\mathrm{MPa})$ & $M$ fixed & $\begin{array}{l}\Delta \sigma_{\mathrm{n}, \mathrm{c}, 95 \%}(\mathrm{MPa}) \\
\text { for } N=2 \cdot 10^{6}\end{array}$ & $\begin{array}{l}\text { FAT acc. } \\
\text { to IIW }\end{array}$ & $\begin{array}{l}\frac{\Delta \sigma_{\mathrm{n}, \mathrm{c} 95 \%}}{\text { FAT }} \\
\text { Improvement } \\
\text { of AW by } \\
\text { HFMI }\end{array}$ \\
\hline BW_AW_SSC_ax & 15 & 469 & 3 & 89 & 90 & 0.99 & $105 \%$ \\
BW_HFMI_SSC_ax & 15 & 469 & 5 & 182 & 160 & 1.14 & \\
BW_AW_SSC_b & 15 & 469 & 3 & 93 & 90 & 1.03 & $155 \%$ \\
BW_HFMI_SSC_b & 15 & 469 & 5 & 237 & 160 & 1.48 & \\
BW_AW_ASW_b & 15 & 469 & 3 & 105 & 90 & 1.17 & $104 \%$ \\
BW_HFMI_ASW_b & 15 & 469 & 5 & 214 & 160 & 1.34 & \\
\hline
\end{tabular}

Fig. 2 Nominal S-N curves with fixed slopes of AW and HFMI-treated butt welds made of S355, SSC pre-corroded (10 days) specimens subsequently dry-tested under cyclic axial tensile loading, comparison with FAT acc. to IIW (AW [7], HFMI [5])

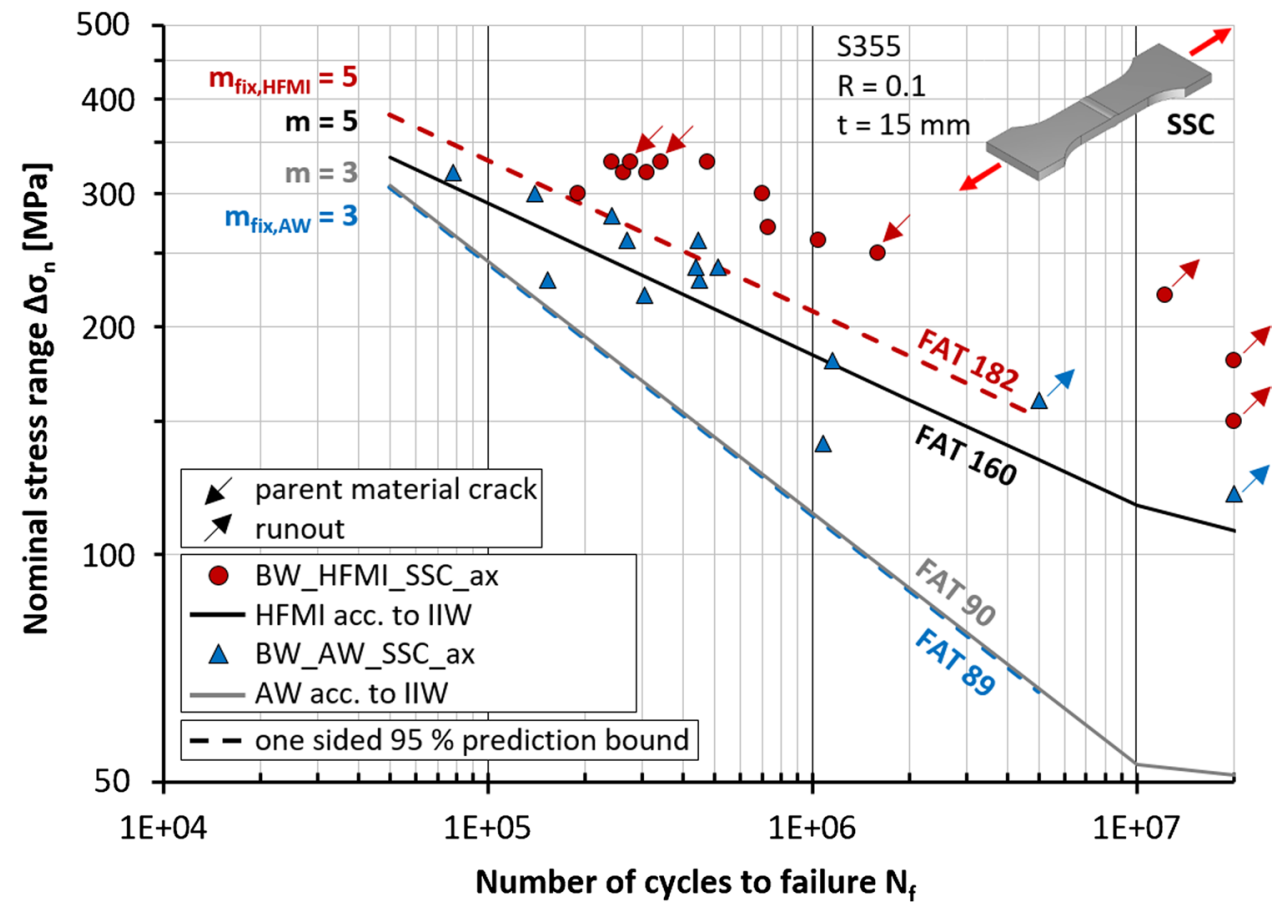

\subsection{Butt welds}

A summary of the fatigue data for all test series on butt welds can be found in Table 2. Figure 2 shows the fatigue test results of butt welds for sequential corrosion in SSC under cyclic axial tensile loading. These test series reproduce the corrosive influence on crack initiation. A corrosive influence on crack growth cannot be simulated by this type of testing. The specimens of both test series all failed in the weld toe. All determined test data of the series $B W_{-}$ $A W \_S S C \_a x$ are above FAT90, which is recommended by IIW [7] for the structural detail butt weld in the as-welded condition. For the test series, FAT89 is calculated; thus, only a small deviation to FAT90 can be determined and a reduction of the FAT classification is not required. A comparison of the test series $B W \_A W \_S S C \_a x$ with $B W \_H F M I \_S S C \_a x$ shows the fatigue strength improvement using the HFMI treatment. In the case of BW_HFMI_SSC_ax, FAT182 is achieved. This results in a 105\% increase in fatigue strength compared to the welded test series being exposed to the same corrosive environment. Furthermore, the test series BW_HFMI_SSC_ax leads to a fatigue strength $14 \%$ above FAT160, which is recommended for HFMI-treated butt welds according to IIW [5] and is consequently also valid for the investigated corrosion method.

The results of butt welds for sequential corrosion by salt spray under cyclic 4-point bending are presented in Fig. 3 . The fatigue life of the test series $B W \_A W \_S S C \_b$ lies significantly above the FAT90 [7] curve and also above the FAT160 [5] curve. As the same corrosion method was applied, this indicates that the increased fatigue life in comparison to the results achieved under axial tensile stress for $B W \_A W \_S S C \_a x$ is attributed to the influence of bending. Nevertheless, FAT93 is obtained for $B W \_A W \_S S C \_b$, which is only slightly above the IIW recommendation for the aswelded condition [7]. In this case, the evaluation based on 

with fixed slopes of AW and HFMI-treated butt welds made of S355, SSC pre-corroded (10 days) specimens subsequently dry-tested under cyclic 4-point bending, comparison with FAT acc. to IIW (AW [7], HFMI [5])
Fig. 3 Nominal S-N curves

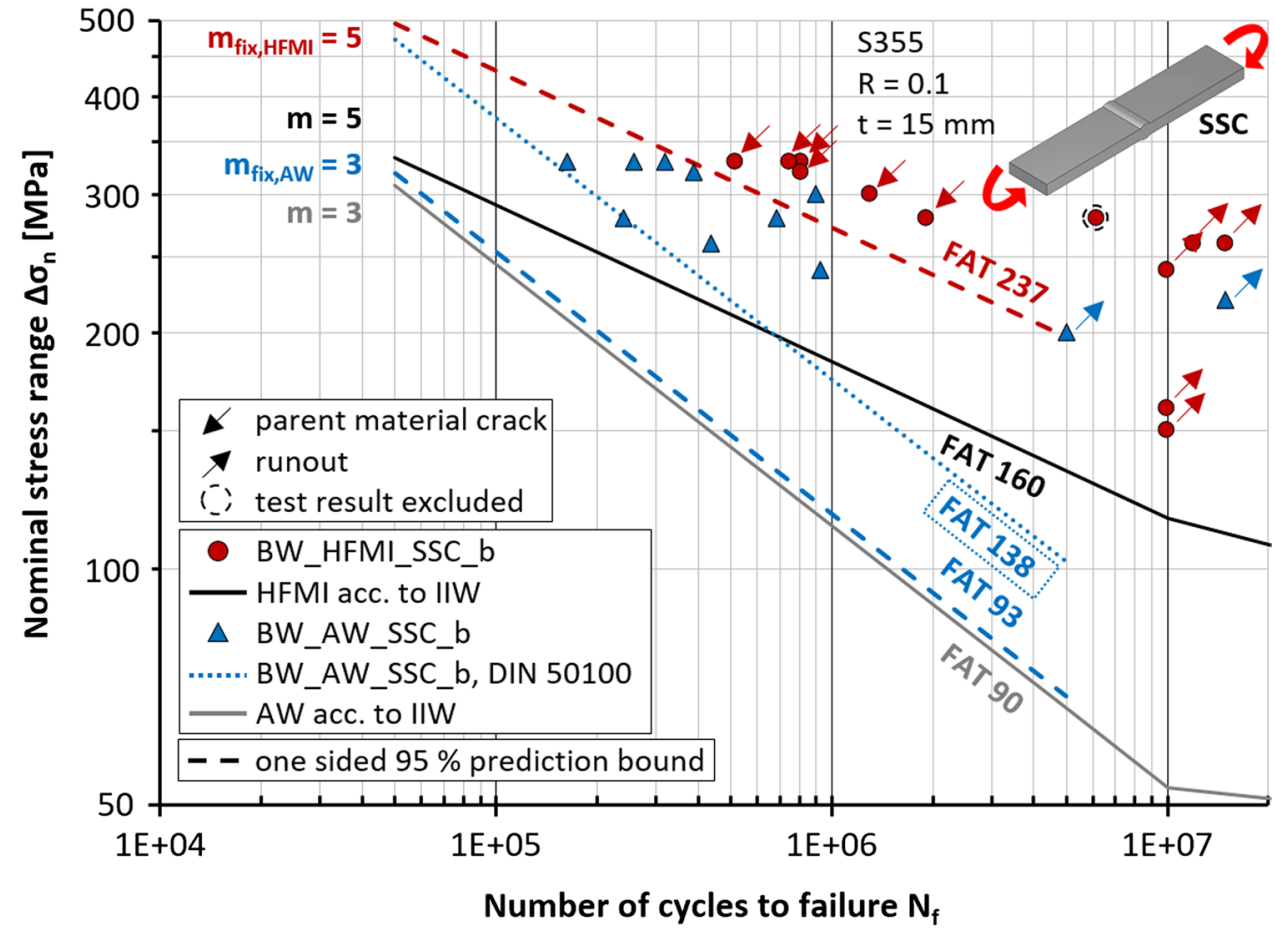

the calculation of the $95 \%$ prediction bound led to an unreasonably conservative fatigue strength value. An additional evaluation according to DIN 50,100 [21] is shown as an example in Fig. 3 and reflects this in the determination of FAT138. It is shown that the choice of the statistical evaluation method for a special distribution of data points leads to strong deviations in the determination of the characteristic fatigue strength. A more detailed analysis of the influence of the evaluation methods will be presented in near future. Nevertheless, the evaluations in this paper are conducted according to the above-mentioned documents and the comparative analyses are carried out consistently for one evaluation method and are therefore inherently valid.

In the case of $B W \_H F M I \_S S C \_b$, all specimens failed in the parent material. One of the specimens failed in the area near to the grip and is therefore excluded from the evaluation. Thus, the HFMI treatment of the weld toe shifts the failure location to the parent material and even higher fatigue life has been achieved compared to the as-welded test series. A classification of the HFMI-treated weld toe is not directly possible. However, these results can be used to determine the lower bound of fatigue strength, as no crack could be detected at the weld toes using dye penetrant testing. FAT237 is calculated for the test series $B W_{-} H F M I_{-}$ $S S C \_b$. The fatigue strength is $48 \%$ higher than the FAT 160 according to IIW [5]. Compared to the as-welded test series $B W \_A W \_S S C \_b$, the fatigue strength could be improved by $155 \%$.

Concerning the results of butt welds of the simultaneous corrosion fatigue tests with artificial seawater under 4-point bending loading, it can be observed that the characteristic curve with FAT105 is $17 \%$ above the curve of FAT90 recommended by IIW [7], see Fig. 4. So, the characteristic fatigue strength of the test series $B W_{-}$ $A W \_A S W \_b$ is also higher compared to both test series for sequential corrosion. Cracks in the parent material also occurred for the as-welded specimens subjected to bending stress. As it has already been discussed in Gkatzogiannis et al. [18] and supported by investigations in Kolitsch et al. [22], it can be assumed that the influence of ASW on crack growth is smaller for smooth-notched structural details like in the case of butt welds. Besides, higher values for the maximum surface roughness were observed in the case of SSC compared to ASW. Moreover, as presented in Ummenhofer et al. [23], corroded butt welds exposed 2 years to real marine conditions in the splash zone showed also a higher fatigue strength compared to uncorroded specimens. The characteristic fatigue strength of the corroded butt welds was $50 \%$ higher compared to the uncorroded condition. Due to the influence of corrosion, smoothening of the weld toe and consequently a reduction of the notch sharpness was documented. The corrosion also reduced the sheet thickness, which assumingly led to a reduction of the residual welding stresses in the areas next to the surface. As for the test series $B W_{-}$ $H F M I \_S S C \_b$, the failure of all specimens of the series $B W \_H F M I \_A S W \_b$ occurred in the parent material. A fatigue class of FAT214 is calculated, which is about $10 \%$ lower than that of the test series $B W_{-} H F M I \_S S C \_b$ but lies also $34 \%$ higher than the FAT 160 proposed by the IIW. 
Fig. 4 Nominal S-N curves with fixed slopes of AW and HFMI-treated butt welds made of S355, ASW pre-corroded (30 days) specimens tested in ASW under cyclic 4-point bending, comparison with FAT acc. to IIW (AW [7], HFMI [5])
Fig. 5 Nominal S-N curves with fixed slopes of transverse attachments made of S355, ASW pre-corroded (30 days) AW and HFMI-treated specimens tested in ASW under cyclic 4-point bending and SSC pre-corroded (10 days) HFMItreated specimens subsequently dry-tested under cyclic axial tensile loading, comparison with FAT acc. to IIW (AW [7], HFMI [5])
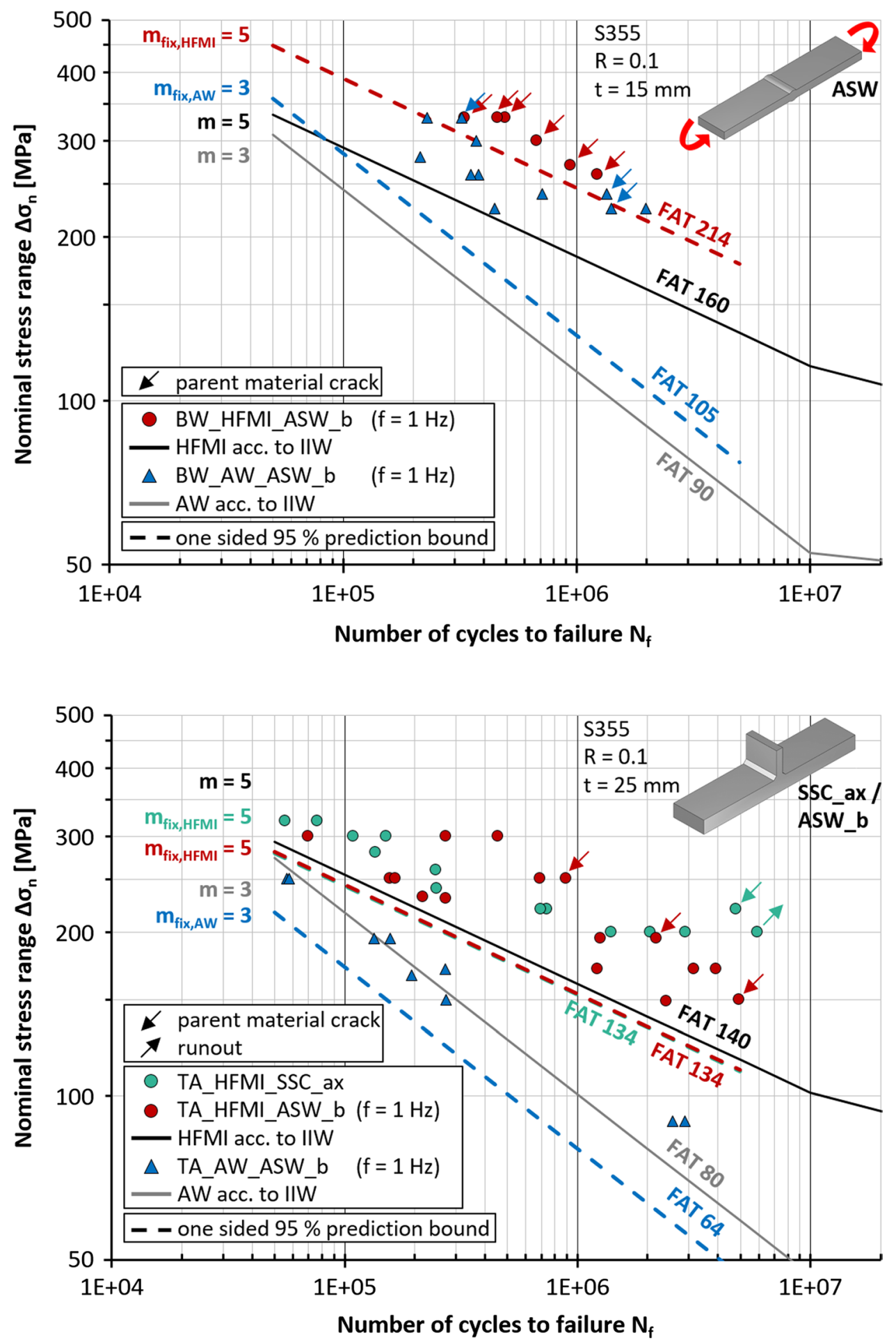

In comparison to $B W \_A W \_A S W \_b$, the HFMI treatment led to an improvement in fatigue strength of $104 \%$.

\subsection{Transverse non-load-carrying attachments}

The fatigue test results of the transverse attachments are presented in Fig. 5, and a summary of the fatigue test data is provided in Table 3. For the as-welded series, $T A \_A W_{-}$ $A S W \_b$ tested in artificial seawater under 4-point bending loading FAT64 is determined. The crack initiation occurred for all tested specimens at the weld toe. Compared to the FAT80 recommended by IIW [7], the characteristic fatigue strength is reduced by $20 \%$ due to the influence of the simultaneous corrosion. Concerning both of the HFMI test series, 
Table 3 Summary of the fatigue data for transverse non-load carrying attachments

\begin{tabular}{|c|c|c|c|c|c|c|c|}
\hline Test series & $t(\mathrm{~mm})$ & $f_{y}(\mathrm{MPa})$ & $m$ fixed & $\begin{array}{l}\Delta \sigma_{\mathrm{n}, \mathrm{c}, 95 \%}(\mathrm{MPa}) \\
\text { for } N=2 \cdot 10^{6}\end{array}$ & $\begin{array}{l}\text { FAT acc. to } \\
\text { IIW }\end{array}$ & $\frac{\Delta \sigma_{\mathrm{n}, \mathrm{c}, 95 \%}}{\mathrm{FAT}}$ & Improvement of AW by HFMI \\
\hline TA_AW_ASW_b & 25 & 369 & 3 & 64 & 80 & 0.80 & $109 \%$ \\
\hline TA_HFMI_ASW_b & 25 & 369 & 5 & 134 & 140 & 0.96 & \\
\hline TA_HFMI_SSC_ax & 25 & 369 & 5 & 134 & 140 & 0.96 & \\
\hline
\end{tabular}

sequential as well as simultaneous corrosion, all test specimens reached a fatigue life which lies above the FAT140 recommended by IIW for the HFMI-treated transverse attachments [5]. The failure location shifted into the parent material on three specimens of the test series TA_HFMI $A S W \_b$ and one specimen of the series TA_HFMI_SSC_ax. The failure of the corroded specimens mainly occurred at the weld toe though. Due to the large scatter of the test results, FAT134 could be obtained for both series, and thus lies $4 \%$ below the FAT140 curve. However, the application of the HFMI treatment has resulted in an increase of the fatigue strength of $109 \%$ compared to as-welded specimens tested under the same loading and corrosion conditions.

It should be noted that two additional test results for the test series TA_HFMI_ASW_b have been obtained since the research project was completed. Therefore, the current test data deviate from those presented in Ummenhofer et al. [8] and Weinert et al. [10]. However, since a slightly higher fatigue strength has been achieved, the previously derived design recommendations are still valid.

\section{Numerical analysis}

The effective notch stress (ENS) approach has been used as a local verification method in addition to the experimental evaluation, to analyse the influence of corrosion on the fatigue strength of HFMI-treated and as-welded specimens. Therefore, the stress concentration at the weld toe has been calculated according to the structural detail and the respective loading type using linear elastic finite element method. Based on the fatigue test data, the effective notch stress $\mathrm{S}-\mathrm{N}$ curves have been derived considering the investigated corrosive environmental conditions. Results for cracks in the parent material were not considered. The statistical evaluation of the characteristic fatigue strength corresponds to the evaluation of the experimental investigations in chapter 3 .

\subsection{Stress concentration factors}

The calculations have been carried out on two-dimensional finite element models in the plane strain state using symmetry conditions, see Fig. 6. Quadratic plane elements (Abaqus: "CPE8") have been used in the software Abaqus.
The basis for the modelled geometry was the nominal values of the test cross sections of the structural details given in Sect. 2.1. For the weld geometry, the parameters of the welding procedure specifications were used. The weld toe is modelled with $\rho_{f}=1 \mathrm{~mm}$ and no indentation depth should be considered according to the IIW recommendations for HFMI-treated welded joints [5]. For meshing, the weld toe 10 quad elements with quadratic shape function were used considering [24]. Linear variable stresses for bending loading and linear constant stresses for axial tensile loading were applied using nominal stress of $1 \mathrm{MPa}$. Thus, the stress concentration $K_{t}$ corresponds directly to the maximum principal stress $S 1$.

Figure 6 shows the results of the linear elastic calculations. The results determined for the butt weld models show that stress concentration is $10 \%$ higher in case of axial tension compared to bending. The linear variable stress distribution due to bending affects the local stress conditions at the edge of the weld toe. For the transverse attachment, the stress concentration due to bending stress is $8 \%$ higher than the stress concentration that was calculated for axial tension. This can be explained by the one-sided transverse attachment. Thus, the centre of gravity is shifted, and the axial tensile loading causes secondary bending effects. This results in additional compressive stresses and reduces the stress concentration at the weld toe.

\subsection{Effective notch stress S-N curves}

The effective notch stress ranges $\Delta \sigma_{k, E N S}$ were calculated considering the determined stress concentrations $K_{t}$ shown in Section 4.1, and the nominal stress ranges $\Delta \sigma_{n}$ that were applied in the fatigue tests. The one-sided $95 \%$ prediction bound was calculated with fixed slopes for the HFMI and the as-welded S-N curves using the fatigue test data. Figure 7 shows the effective notch stress $\mathrm{S}-\mathrm{N}$ curves of the HFMI and the AW specimens investigated under the corrosive influences presented in this study. The results are compared to the FAT classes FAT320 and FAT225 recommended by IIW for the HFMI [5] and the as-welded [7] cases respectively.

The fatigue test data are evaluated for the as-welded butt welds under cyclic axial tensile loading and cyclic bending loading for sequential corrosion ( $B W_{-} A W_{-} S S C \_a x$, $\left.B W \_A W \_S S C \_b\right)$ together with the as-welded butt welds 


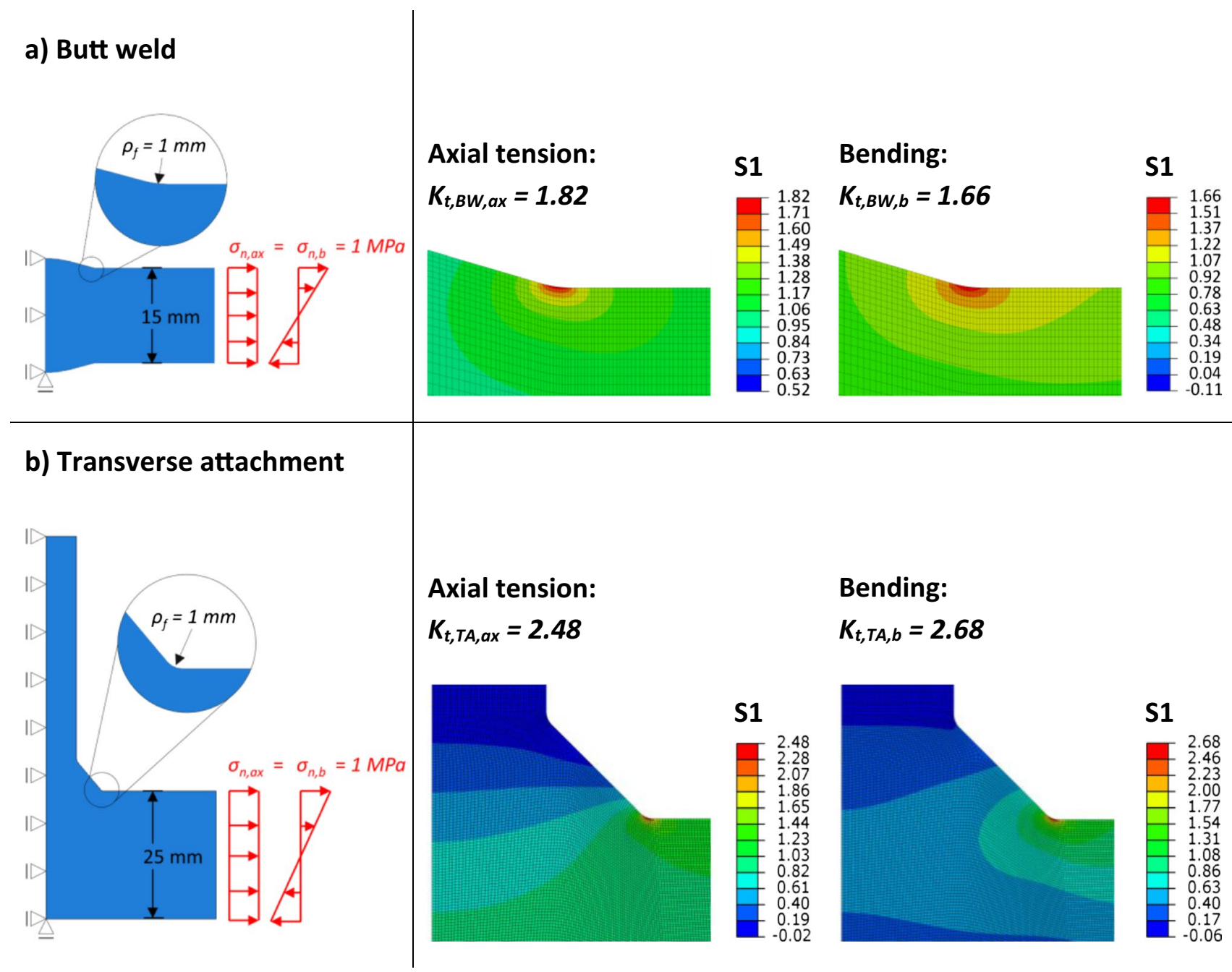

Fig. 6 Numerical models, results for principal stress S1 and stress concentrations $\mathrm{K}_{\mathrm{t}}$. a Butt weld. b Transverse attachment

under cyclic bending loading for simultaneous corrosion $\left(B W \_A W \_A S W \_b\right)$. For the test series of AW butt welds, FAT182 is achieved. The characteristic S-N curve lies 19\% below FAT225 for the as-welded condition according to IIW [7]. It is obvious that this is due to the results of the test series $B W \_A W \_S S C \_a x$. On the other hand, all fatigue data presented in Sect. 3.1 of AW butt welds evaluated by the nominal stress approach are above FAT 90 according to IIW. In other investigations of uncorroded butt welds, the FAT225 based on the ENS concept was also not achieved (e.g. [25, 26]). These studies give an overview about further publications on this topic. Pedersen et al. [26] investigate this aspect in more detail using a large database and show that applying the ENS concept to thin butt welds $(t<20 \mathrm{~mm})$ can lead to a non-conservative assessment due to low stress concentrations $\left(K_{t}<2.0\right)$. Based on the investigations of Sonsino et al. [27], it is proposed to maintain the FAT225 and to provide a flatter slope of $m=5$ for consideration within the ENS concept. Pedersen et al. [26] show that this approach leads to a strongly conservative estimate in the area of the medium to low cycle fatigue area. Zhang and Maddox [28] recommend a general reduction to the FAT190 based on their research. Anyhow, the FAT182 determined in the present study would not fulfil this recommendation either. The fact that even a reduced FAT class could not be achieved could be attributed to the influence of corrosion. This is in correlation with the fact that results of the series $B W \_A W_{-} S S C \_a x$ based on nominal stresses are also not significantly above the recommended FAT class. A nominal stress based comparison of this series with uncorroded specimens presented in Gkatzogiannis et al. [11] supports this thesis, as a corrosionrelated reduction in fatigue strength of $18 \%$ could also be determined. Nevertheless, further studies on butt welds are necessary to make a valid statement.

For fillet welds of transverse attachments in the aswelded condition, Pedersen et al. [26] state that the ENS results are in good agreement with FAT225. This also applies to the results based on nominal stresses regarding 
Fig. 7 Effective notch stress S-N curves for HFMI-treated and as-welded specimens made of S355 taking into account corrosive environmental conditions, comparison with FAT acc. to IIW (AW [7], HFMI [5])

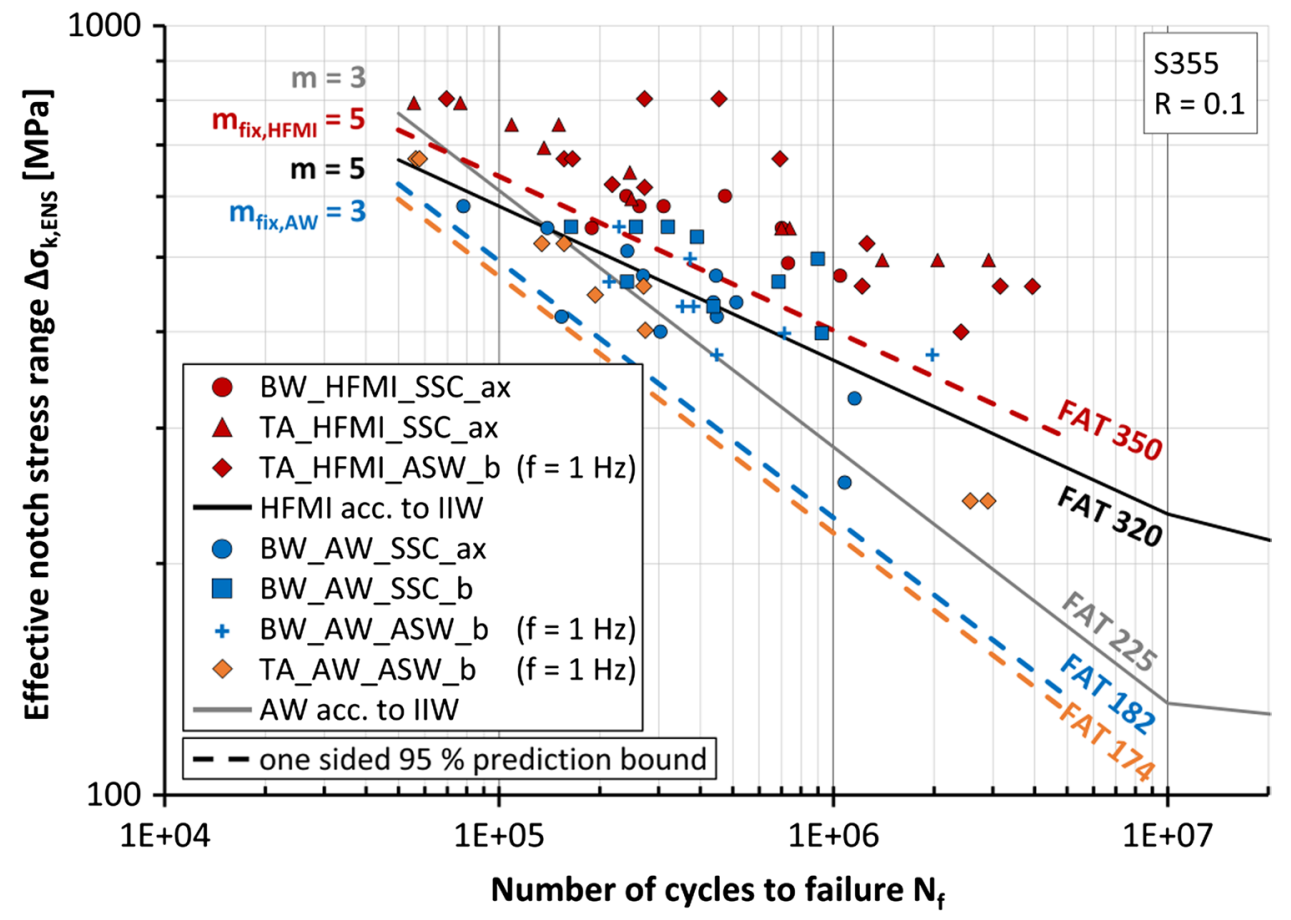

FAT80. Therefore, the series $T A \_A W \_A S W \_b$ is evaluated separately to the butt weld series and a comparison with FAT225 is considered appropriate for this case. FAT174 is determined for this series and is thus $23 \%$ below the IIW recommendation. The effective notch stress fatigue resistance for as-welded structural details given in Hobbacher [7] covers non-corrosive environments, so it can be assumed that the reduction is caused by the corrosive conditions. Consequently, the application of FAT225 is not conservative in the case of corrosive influences from artificial seawater examined in this study. It is important to note that in the context of this study, the evaluation is limited to nine data points. The evaluation of a larger amount of data is necessary to avoid an over-conservative and thus uneconomical assessment.

The fatigue test data were evaluated for the HFMI-treated butt welds and transverse attachments under axial loading for sequential corrosion (BW_HFMI_SSC_ax, TA_HFMI_ SSC_ax) combined with the HFMI-treated transverse attachments under bending for simultaneous corrosion $\left(T A \_H F M I \_A S W \_b\right)$. The joint evaluation of both structural details is motivated by ENS investigations of Yildirim [29] on uncorroded and HFMI-treated butt welds. Among others, the applicability of FAT320 was confirmed for the HFMI-treated butt welds from [30] with low notch sharpness and similar thickness to the specimens investigated here. The data points of the HFMI-treated specimens examined here are also above the FAT320. Moreover, based on the characteristic curve and the determined fatigue strength of FAT350 for the HFMI test series, the recommendation of
IIW [5] is confirmed. The comparison of the determined notch stress strengths with the strengths of HFMI-treated structural details according to IIW [5] initially allows the assumption that the FAT320 is also valid for the HFMItreated specimens under the investigated influences of corrosion. Compared to FAT320 for HFMI, no negative influence from corrosion can be observed. Thus, the use of the IIW recommended class in Marquis and Barsoum [5] also corresponds to a conservative approach for the analysed corrosion methods.

\section{Conclusions and outlook}

The effectiveness of the HFMI treatment to improve the fatigue strength of welded structural details of steel grade S355 exposed to corrosive environments has been investigated experimentally and numerically. Furthermore, the applicability of the design curves recommended by IIW for as-welded and HFMI-treated details was evaluated for the case of corrosive exposure. To investigate in the laboratory the influence of marine corrosion on the phases of crack initiation and crack growth individually, sequential corrosion with salt spray and simultaneous corrosion with artificial seawater were applied respectively. Corrosion fatigue tests at a stress ratio $R=0.1$ were carried out under cyclic axial tensile loading and cyclic 4-point bending loading on specimens in the as-welded and HFMI-treated condition for the determination of fatigue strength. The tests were conducted on butt weld and transverse non-load carrying attachment 
specimens with a sheet thickness of $t=15 \mathrm{~mm}$ and $t=25 \mathrm{~mm}$ respectively. Based on the experimental investigations and the evaluation using the nominal stress approach, the following conclusions can be drawn:

No considerable reduction of fatigue strength could be determined for all fatigue test series of corroded as-welded butt weld specimens in comparison with the IIW recommendation FAT90.

The results for HFMI-treated butt welds showed no corrosion-induced reduction of fatigue strength compared to FAT160 according to IIW. In contrary, for all test series, the corresponding FAT classes determined were between 14 and $48 \%$ above the design proposal. However, the applied maximum fatigue strength should not exceed that of the parent material. An adaptation of the existing assessment proposal is thus not required. An improvement of FAT90 for as-welded by five FAT classes to FAT160 due to HFMI treatment is still valid.

For the as-welded transverse attachments, a reduction in fatigue strength of $20 \%$ concerning FAT 80 according to IIW could be observed due to simultaneous corrosion.

The fatigue strength obtained for HFMI-treated transverse attachments during sequential and simultaneous corrosion testing is $4 \%$ below the FAT class 140 according to IIW. The reduction by one class to FAT125 is recommended to consider the investigated types of corrosion. Thus, an improvement of FAT80 for the as-welded condition by four FAT classes to FAT125 due to HFMI treatment is viable.

The HFMI post-weld treatment increases the fatigue strength of butt welds and transverse attachments even if exposed to the investigated corrosive environmental conditions. For butt welds, the increase in fatigue strength is between 104 and $155 \%$ based on the results of the corresponding corroded as-welded specimens. An improvement of $109 \%$ was determined for the transverse attachment specimens.

It can be determined that a corrosion-related reduction in fatigue strength depends on the notch sharpness of the structural detail. A more pronounced reduction for the transverse attachments can be observed, especially for simultaneous testing in artificial seawater. In comparison, no considerable influence of corrosion on fatigue strength could be identified for butt welds.

In addition, the notch stress approach was used as a local analysis method to verify the applicability of the existing design proposals. Based on the test results and the calculated effective notch stress curves, the as-welded and HFMItreated structural details exposed to corrosive environments could be classified. Based on the numerical investigations, the following can be concluded:

An evaluation using the notch stress approach includes all as-welded test specimens, whose cracks initiated at the weld toe, shows a fatigue strength-reducing influence of corrosion in case of transverse attachments. The results show that the characteristic fatigue strength for a fixed slope of $m=3$ is FAT174, which lies $23 \%$ below the FAT class 225 proposed by IIW. Therefore, the application of the design curve FAT225 is not possible in the case of corrosion conditions without further modifications. Nevertheless, the evaluation of a larger amount of data is necessary to provide a valid statement and to avoid an over-conservative and thus uneconomical assessment. This also applies to butt welds to verify a general applicability of FAT225. Thus, a valid assessment of corrosion-related reductions could be made on an ENS basis for butt welds.

It is evident that the notch stress approach is conservative and can be applied to HFMI-treated structural details under conditions of sequential and simultaneous corrosion investigated in this study. Since FAT350 for a fixed slope of $m=5$ was determined, the recommendation of IIW for FAT320 is validated.

The investigations carried out so far cover a uniform corrosion-related thickness loss of up to $0.1 \mathrm{~mm}$. Future research will focus on the influence of higher thickness reductions on the residual stress fields and the surface layer.

Acknowledgements The authors would like to thank the funding institution and the research association as well as the project committee for their support.

Funding Open Access funding enabled and organized by Projekt DEAL. The IGF project 18.457 N/DVS number 09.069 of the Research Association on Welding and Allied Processes was funded by the German Federation of Industrial Research Associations ("Arbeitsgemeinschaft industrieller Forschungsvereinigungen," AiF) within the framework of the programme for the promotion of Industrial Collective Research ("Industrielle Gemeinschaftsforschung," IGF) of the Federal Ministry for Economic Affairs and Energy based on a decision by the German Bundestag.

Open Access This article is licensed under a Creative Commons Attribution 4.0 International License, which permits use, sharing, adaptation, distribution and reproduction in any medium or format, as long as you give appropriate credit to the original author(s) and the source, provide a link to the Creative Commons licence, and indicate if changes were made. The images or other third party material in this article are included in the article's Creative Commons licence, unless indicated otherwise in a credit line to the material. If material is not included in the article's Creative Commons licence and your intended use is not permitted by statutory regulation or exceeds the permitted use, you will need to obtain permission directly from the copyright holder. To view a copy of this licence, visit http://creativecommons.org/licenses/by/4.0/.

\section{References}

1. Price S, Figueira R (2017) Corrosion protection systems and fatigue corrosion in offshore wind structures: current status and future perspectives. Coatings 7(2) 
2. Revie RW, Uhlig HH (2008) Corrosion and corrosion control: an introduction to corrosion science and engineering, 4th edn. John Wiley \& Sons Inc, Hoboken

3. Adedipe O, Brennan F, Kolios A (2016) Review of corrosion fatigue in offshore structures: present status and challenges in the offshore wind sector. Renew Sustain Energy Rev 61:141-154

4. Yildirim HC, Marquis GB (2012) Overview of fatigue data for high frequency mechanical impact treated welded joints. Weld World 56(7-8):82-96

5. Marquis GB, Barsoum Z (2016) IIW Recommendations for the HFMI treatment for improving the fatigue strength of welded joints, 1st Edition, Singapore

6. DNVGL-RP-C203 (2016) Fatigue design of offshore steel structures

7. Hobbacher A (2016) Recommendations for fatigue design of welded joints and components, 2nd edn. IIW Collection, Springer, Cham

8. Ummenhofer T, Engelhardt I, Knödel P, Gkatzogiannis S, Weinert J, Löschner D (2018) Erhöhung der Ermüdungsfestigkeit von Offshore-Windenergieanlagen durch Schweißnahtnachbehandlung unter Berücksichtigung des Korrosionseinflusses [Increase of Fatigue Strength of Offshore Wind Energy Power-Plants through Post-weld Treatment in consideration of Corrosion Influence]; Research project, IGF-Nr.: 18.457 N / DVS-Nr.: 09.069, Final Report

9. Weinert J, Gkatzogiannis S, Engelhardt I, Knödel P, Ummenhofer T (2018) Erhöhung der Ermüdungsfestigkeit von geschweißten Konstruktionsdetails in korrosiver Umgebung durch Anwendung höherfrequenter Hämmerverfahren. Schweißen und Schneiden 70(11):782-789

10. Weinert J, Gkatzogiannis S, Engelhardt I, Knödel P, Ummenhofer T (2019) Increasing the fatigue strength of welded structural details in corrosive environments by applying high frequency mechanical impact treatment. Weld Cut 18(6):458-464

11. Gkatzogiannis S, Weinert J, Engelhardt I, Knoedel P, Ummenhofer T (2021) Corrosion fatigue behaviour of HFMI-treated butt welds. Int J Fatigue 145:106079

12. Weinert J, Gkatzogiannis S, Engelhardt I, Knoedel P, Ummenhofer $T$ (2021) Investigation of corrosive influences on the fatigue behaviour of HFMI-treated and as-welded transverse non-loadcarrying attachments made of mild steel S355. Int J Fatigue 151:106225

13. DIN EN ISO 9227, 07-2017: Corrosion tests in artificial atmospheres - Salt spray tests (ISO 9227:2017); German version EN ISO 9227:2017-07

14. ASTM D1141-98: Standard Practise for the Preparation of Substitute Ocean Water

15. Adedipe O, Brennan F, Kolios A (2015) Corrosion fatigue load frequency sensitivity analysis. Mar Struct 42:115-136

16. Oberparleiter W (1986) Einfluß von Prüffrequenz und Salzgehalt des Korrosionsmediums auf die Korrosionsermüdung von Stählen bei betriebsähnlichen Lastabläufen. Mater Corros/Werkst Korros 37(7):391-397
17. Weich I (2009) Ermüdungsverhalten mechanisch nachbehandelter Schweißverbindungen in Abhängigkeit des Randschichtzustands. Technische Universität Braunschweig, PhD-thesis

18. Gkatzogiannis S, Weinert J, Engelhardt I, Knoedel P, Ummenhofer T (2019) Correlation of laboratory and real marine corrosion for the investigation of corrosion fatigue behaviour of steel components. Int J Fatigue 126:90-102

19. Euler M, Kuhlmann U (2014) StatisticaI intervals for evaluation of test data acc. to Eurocode 3 Part 1-9. 3rd draft. Contribution to Working Group 6.3: StatisticaI Analysis of Fatigue Data ECCS TechnicaI Committee 6 - Fatigue. Stuttgart

20. DIN EN 1993-1-9, 2010-12: Eurocode 3: Design of steel structures - Part 1-9: Fatigue; German version EN 1993-1-9:2005 + AC:2009

21. DIN 50100, 2016-12: Load controlled fatigue testing - Execution and evaluation of cyclic tests at constant load amplitudes on metallic specimens and components (english title)

22. Kolitsch S, Gänser H-P, Pippan R (2016) Determination of crack initiation and crack growth stress-life curves by fracture mechanics experiments and statistical analysis. Procedia Struct Integr 2:3026-3039

23. Ummenhofer T, Gkatzogiannis S, Weidner P (2017) Einfluss der Korrosion auf die Ermüdungsfestigkeit von Konstruktionen des Stahlwasserbaus

24. Fricke W (2012) IIW recommendations for the fatigue assessment of welded structures by notch stress analysis, Woodhead Publishing Ltd., IIW-2006-09, Cambridge

25. Weidner P (2020) Zum Ermüdungsverhalten einseitig geschweißter Stumpfstöße von Kreishohlprofilen, PhD-thesis, Karlsruher Institut für Technologie (KIT)

26. Pedersen MM, Mouritsen O, Hansen MR, Andersen JG, Wenderby J (2010) Re-analysis of fatigue data for welded joints using the notch stress approach. Int J Fatigue 32(10):1620-1626

27. Sonsino CM, Bruder T, Baumgartner J (2010) S-N Lines for Welded Thin Joints - Suggested Slopes and FAT Values for Applying the Notch Stress Concept with Various Reference Radii. Weld World 54(11-12):R375-R392

28. Zhang Y-H, Maddox SJ. Estimating Long-Endurance Fatigue Strength of Girth-Welded Pipes Using Local Stress Approach. 33rd International Conference on Ocean, Offshore and Arctic Engineering, OMAE. San Francisco, California, USA. June 8-13, 2014. New York: American Society of Mechanical Engineers

29. Yildırım HC (2014) Fatigue strength assessment of HFMI-treated butt welds by the effective notch stress method. Weld World 58(3):279-288

30. Ummenhofer T (2009) REFRESH: Lebensdauerverlängerung bestehender und neuer geschweißter Stahlkonstruktionen [REFRESH: Extension of the fatigue life of existing and new welded steel structures]; research project, final report D 761, KIT Steel \& Lightweight Structures, Research Center for Steel, Timber \& Masonry, Karlsruhe, Germany

Publisher's note Springer Nature remains neutral with regard to jurisdictional claims in published maps and institutional affiliations. 